\title{
Effect of CEO Power on Executive Pay-Performance Sensitivity: A literature Review
}

\author{
Changzheng Zhang ${ }^{a}$ Zhuoqin Gao ${ }^{\mathrm{b}}$ \\ Xi'an University of Technology, School of Economics \& Management, Shanxi Xi'an, 710054, China \\ a zcz7901@163.com, b 952623209@qq.com
}

Keywords: CEO Power; Executive pay-performance sensitivity (EPPS); Manipulation Effect; Executive Compensation; Literature review

\begin{abstract}
In order to reconcile the conflicting conclusions of research on the manipulation effect of CEO power on executive pay-performance sensitivity (EPPS) and further promote the research progress, the method of literature review is adopted by investigating and discussing the latest studies on this topic in detail. According to the review, as a result of interdisciplinary combination and theoretical integration, CEO power theory can actually explain the reality of low and asymmetric EPPS more effectively than traditional principal-agent theory, and the research of EPPS based on CEO power perspective should become the mainstream in this topic. Review results also show that manipulation effect of CEO power on EPPS does exist across the world. However, the strength and nature of such manipulation effect have not been recognized clearly. It is the newest trend to recognize that the manipulation effect of CEO power on EPPS is a kind of "contingent effect" instead of "absolute effect". In the future, more scholars should discuss the critical contingent variables that can affect the relationship between CEO power and EPPS in depth, such as CEO tenure.
\end{abstract}

\section{Introduction}

The topic on the effect of CEO power on executive compensation started in the late 1980s, developed in the early 2000s, and showed as an intense boost in recent few years. The research on executive compensation from the perspective of CEO power has already been nearly mature. Different with western countries, the separation of ownership and control for Chinese enterprises has happened very rapidly with the top-down enforcement of enterprise reform policies in a short period. Due to the shortage of experiencing the natural development process of market economy for a long period, executive compensation system in China has evolved too hurriedly, and the process even can be viewed as spoiling it by excessive enthusiasm (M. Jian, K.W. Lee) ${ }^{[1]}$. Such a fact leads to the emergent issues of "insider control" and "agent cost" during the evolution process of corporate governance, and all kinds of strange and improper executive compensation chaotic phenomena has come out in an unending flow. All these facts show that both the CEO power constraints and executive compensation incentive mechanism are ineffective at all. The practical unexplained problems on executive compensation issue make theoretical circles in China reflect the effectiveness of traditional principal-agent theory on explaining executive compensation. Based on the reflection, they begin to focus on the new trends in investigating executive compensation by applying CEO power theory. Such a new perspective has great practical and theoretical meanings in improving CEO power theory and executive compensation theory and further practically enhancing corporate governance quality. At present, CEO power theory has been developed into a mainstream theoretical perspective, treated the same as the classical optimal contract theory within the framework of principal-agent, from a fresh research perspective in studying executive compensation. In other words, CEO power theory has gradually been receiving more and more attention from scholars (F.H. Xiong, Y. Peng, 2012) ${ }^{[2]}$.

According to CEO power theory, as the rational economic person who pursuing the maximization of his interests, CEO can manipulate all kinds of management and operating mechanisms inside 
enterprises by running his power delegated by the boards and shareholders, in which executive compensation mechanism is naturally included. Therefore, CEO power and executive compensation are not two independent corporate governance mechanisms. To a large degree, because the implementation of CEO power would affect the formation process, final results and enforcement effectiveness of executive compensation contract, and further lead to the practical deviation from theoretical optimal contract. Therefore, current CEO power can influence executive compensation essentially (B. Lucian, F. Jesse, 2010) ${ }^{[3]}$. Such a conclusion is expressed in governance practices as that, CEO with higher power can discretionally determine each dimension of his own compensation package, and specifically make use of both the formal power delegated to himself and informal influence derived from the power to manipulate the boards in order to acquire extra compensation besides the normal rewards. Consequently, with the perspective of CEO power theory, executive compensation is not only a tool revolving the problem of principal-agent, but it itself may be part of the agent problem. Till now, much literature has described and explained the manipulation effect of CEO power on executive compensation from its four core dimensions, respectively compensation level, compensation-performance sensitivity, compensation gap among executives and executive-employees compensation gap. The existing research results make good contributions to theoretical research in strategic human resource management and corporate governance, and provide deep insights and excellent suggestions to the practical enterprises operations.

Compared with the dimensions of compensation level, compensation gap among top executives and executive-employees compensation gap, the studies about executive pay-performance sensitivity (EPPS) from the perspective of CEO power theory have not reached a consensus, and there are still many disputes on this issue. Such conflicting theoretical research results can't provide clear guide for the governance practices in this executive compensation issue. As a result of interdisciplinary combination and theoretical integration, the study of EPPS based on CEO power perspective has become the mainstream of the decision mechanism of EPPS. It has integrated core ideas of three popular theories, respectively corporate governance theory, strategic management theory and human resources management theory, thus it is of both prospective and inherited characteristics. Therefore, the paper tries to review the related literature on the manipulation of CEO power on EPPS, attempts to take over from the past and set a new course for the future in this topic.

\section{Research progress on the manipulation effect of CEO power on EPPS}

EPPS is regarded as the critical index in measuring the effectiveness of executive compensation contract, and it is also the dimension receiving the most attentions from the public and the government. Both the CEO power theory and the governance practices indicate that the boards and shareholders can not control the design of executive compensation contract completely, and CEO has both the motivations and capability to affect the setting process of EPPS. In Fig.1, the link between CEO power and firm performance is represented as EPPS, and ME means the manipulation effect of CEO power on EPPS. At present, there are three basic views on the relationship between CEO power and EPPS, i.e. ME in Fig.1, according to the existing studies.

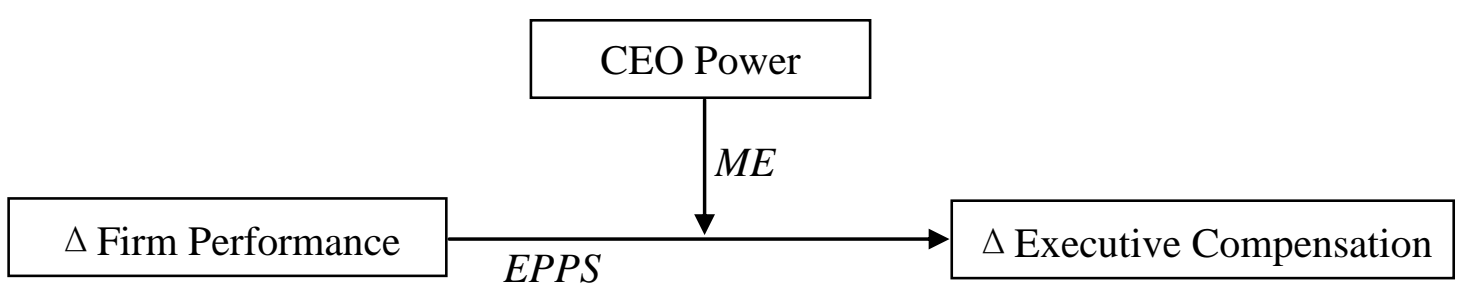

Figure. 1 A Conceptual Model on the Manipulation Effect of CEO Power on EPPS 
First, there is a positive effect. Both the theoretical and empirical literature ever proves that with the increase of CEO power, EPPS will be stronger. For example, G. Simon et al.(2011) ${ }^{[4]}$ have constructed a theoretical model on the relationship among CEO over-confidence, compensation contract and capital budgets, which indicates that for CEO with higher power, though objectively firm performance is affected by uncontrollable factors to a large degree, he would believe that the running of his power will bring better performance to the firm because of his over-confidence in manipulating firm performance. Therefore, CEO with higher power and over-confidence would require higher EPPS in setting his own compensation. Based on theoretical model analysis, A.M. Zai and S.R. Zhang (2013) ${ }^{[5]}$ further take Chinese listed firms in 1998-2011 as the sample, and empirically confirm that CEO power would positively enhance the compensation reaction to better performance indexes. X.F. Quan, S.N. Wu and F. Wen (2010) have adopted the Chinese listed state-owned firms in 2004-2007 as the sample and confirmed that the positive effect of CEO power on EPPS is still obvious in the background of state-owned firms.

Second, there is a negative effect. As the main founders of this view, Gomez-Mejia et. al. (1987) propose that due to the self-serving nature of CEO, CEO with higher power has the capability and motivations to reflect his favor in firm size and risk aversion in compensation contract, and thus EPPS will be much lower than normal. Saltuk Ozerturk (2005) further constructs an executive compensation decision model, in which the independence of the boards is affected by CEO power. Based on the model, he derives a conclusion that CEO power is negatively related with EPPS. C.Z. Zhang, and K. Gan (2012) ${ }^{[6]}$, two Chinese scholars, construct EPPS model based on CEO power from the perspective of internal corporate governance structure, and further prove that CEO power can negatively manipulate EPPS based on the model analysis. Such a conclusion has received many supports of the other studies (D. Lin et al., 2013) ${ }^{[7]}$.

Third, there is a contingent effect. In order to reconcile the above different conclusions on the relationship between the two, some scholars have abandoned the view of "absolute effect" and then attempt to pursue the view of "contingent view". For example, certain literature has taken firm performance as the contingent factor and confirmed that the effect of CEO power on EPPS is actually determined by firm performance. The growth degree of executive compensation when performance grows is much higher than the decrease degree when performance decreases. Such an asymmetry of compensation change derived from the self-serving motivations of CEO power implementation is called as compensation stickiness (B. Dai Bin et al, 2011; J.X. Fang, 2009) ${ }^{[8,9]}$. Some scholars take CEO personality characteristics as the contingent factor and point out the effect of CEO power on EPPS will depend on the difference of CEO's risk preference (Dai Z. et al., 2014) ${ }^{[10]}$.

\section{Research review on the manipulation effect of CEO power on EPPS}

Though the present studies have generally found out and acknowledged the manipulation behavior of CEO power on EPPS, there are great disputes on the specialized manipulation strength and manipulation orientation of CEO power on EPPS among different scholars. Specifically speaking, it can be mainly divided into three schools. Firstly, positive view is mainly based on the assumption of being risk neutral for CEO, and this view regards that CEO power has both the motivations and capability to improve EPPS; Secondly, negative view is mainly based on the assumption of being risk aversion for CEO, and this view regards that CEO power has the intention and capability to decrease EPPS; Thirdly, contingent view argues that CEO's risk bear is determined by many critical factors, such as strategy choice, former performance, monitoring intensity and CEO leadership style, and so on, and the effect of CEO power on EPPS is different with the change of the contingent factors.

A closer scrutiny will show that the former two views are gradually declining, while more and more scholars are intending to recognize that contingent view is more suitable for the investigation on the relationship between CEO power and EPPS. Many scholars have accepted that research results based 
on this view are deeper in depth, and have better contribution in guiding the executive compensation practices. Chinese scholars have already done great work in this field, however, compared with their peers all over the world, the research contribution from the perspective of contingent view is still rather weak, which actually needs much further progress in the near future.On the whole, the research in this field expresses the following three characteristics.

Firstly, from the perspective of the object of study, the regional background of the samples has gradually expanded from American into the Europe, and also developed from the developed countries to developing countries, and what is more, the comparative study across different countries has emerged. The industry background of the samples has expanded from a single industry into muti-industries, and the comparative study across different industries is increasingly becoming the focus of the future research.

Secondly, from the perspective of study methods, theoretical study and empirical study are both adopted, while empirical study is taken as the main method. What is more, the design of the empirical study has experienced a development process from extensive to elaborate and from simple to complex, which improves the effectiveness of research method significantly. Specifically speaking, the improvement show as three aspects. (1)With the enhancement of regulation on executive compensation disclosure (A. B. Mark, 2013) ${ }^{[11]}$, the first improvement is that the measures of critical variables, such as CEO power, EPPS and other important control variables, get more diverse and refined, (2)the second is that the choice of control variables and moderating variables gets more clearly and systematic, (3)and the third is that the data analysis methods' adoption gets more accurate and complex. For example, the data analysis methods not only include simple correlation analysis, variance analysis and linear regression analysis, but include more complex structural equation model which allows measurement error, and simultaneous equations model which is more precise.

Thirdly, from the perspective of research results, scholars have primarily reached an consensus on the existence of the manipulation effect of CEO power on EPPS. Besides, more and more literature begins to pay more attention to the role of executives' psychological and behavioral factors in manipulating EPPS. As a result, the existing studies have provided several kinds of competing explanations of both practical and theoretical values on the producing mechanism of the manipulation effect, which can be tested in the future research. It can be said that CEO power theory, just very similar as the so-called optimal contract theory, has changed into the mainstream perspective in investigating executive compensation, especially in EPPS, from a new emerging perspective. To a certain degree, CEO power theory even receives more attention from the scholars then the optimal contract theory. CEO power theory has provided good contribution to the issue of executive compensation both practically and theoretically.

The present studies also show that no matter positive effect, negative effect or contingent effect, CEO power manipulates EPPS by adopting different behavioral mechanisms. For example, CEO with higher power would implement the following methods to make the boards and shareholders decide to give CEO more compensation out of the consideration of risk control or value rewards, or even to determine EPPS himself instead of the boards, and thus finally realize the intention of manipulating EPPS. First, CEO with higher power can modify the compensation contract post-performance-realization (J. L. Garner, T.D. Harrison, 2013) ${ }^{[12]}$; Second, CEO with higher power can choose and execute strategic decisions of higher risk and complexity (F.H. Xiong, Y. Peng, 2012) ${ }^{[2]}$, which can adjust EPPS according to his own favor; Third, CEO with higher power can choose the performance criteria confirming to his own interest and favor from a wider range by adopting the firm stakeholder theory (Christiane Alcouffe, 2000), which can link the compensation to the best performance criteria no matter how bad the other performance criteria are. The topics on the running effectiveness of the manipulation ways will be the focus in this field in the near future. 


\section{Summary}

The paper reviews the literature on the effect of CEO power on EPPS. It can be learned that there are many disputes in this topic. The contributions of the present studies can be concluded as three aspects: (1) the manipulation effect of CEO power on EPPS does exist both in China and the developed countries; (2)the strength and nature of manipulation effect of CEO power on EPPS has not been recognized clearly across all the scholars, some argue positive effect, some argue negative, and some argue contingent effect; (3)there are a variety of ways for CEO to manipulate EPPS, each of which has special application conditions and is to be suitable for CEO of specialized characteristics.

In conclusion, it can be found that there are three research trends in this field. First, deep development in the research on this field should be emphasized further. With the studies in this field grow mature gradually, the research topic gets more refined, the research context gets more specific, the research method gets more diverse, the research content gets deeper, the measure of variables gets more precise, and the explanations on the manipulation mechanisms of CEO power on EPPS get more multivariant. Second, comparative study should be enhanced further. With the development of the research, comparative study method has increasingly been applied in the research of this field in order to better know the nature of the manipulation effect of CEO power on EPPS, and further get new findings of great value. For example, many scholars begin to comparatively discuss the similarities and differences of the manipulation effects of CEO power on EPPS under different conditions, such as different countries, different industries, different regions, and different ownership properties, and so on. The last but not the least, contingent perspective should be emphasized further. It is the newest trend to recognize that the manipulation effect of CEO power on EPPS is a kind of "contingent effect" instead of "absolute effect". More and more scholars begin to discuss the critical contingent variables. Of all the potential contingent variables, we argue that CEO tenure may be the most important one, which needs great attention from the scholars both foreign and Chinese.

\section{Acknowledgements}

This research was supported by the Scientific Research Foundation of Ministry of Education of the PRC in Humanities and Social Sciences under Grant "14YJA630089" and 13YJAZH123", and the Shanxi Social Science Foundation under Grant "2014P04".

\section{References}

[1] M. Jian, and K.W. Lee: CEO compensation and corporate social responsibility, Journal of Multinational Financial Management, Vol.29, (2015) No.1, p.46-65.

[2] F.H. Xiong, and Y. Peng: Research on the Effect of Managerial Power on Executive Compensation, Research on Financial and Economic Issues, (2012) No. 10, p.123-128. (In Chinese)

[3] B.Lucian, and F. Jesse: Pay without Performance: The Unfulfilled Promise of Executive Compensation (Harvard University Press, American 2004).

[4] G. Simon, J.B. Heaton, and O. Terrance: Overconfidence, Compensation Contracts, and Capital Budgeting, The Journal of Finance, Vol.66 (2011) No.5, p.1735-1777.

[5] Zai Aimei, Zhang Shuran, Study on the Managerial Power and Incentive Compensation Manipulation, Journal of Sun Yat-Sen University, Vol.53 (2013) No.5, p.190-208.

[6] C.Z. Zhang, and K. Gan: Proc. Management, Manufacturing and Materials Engineering (Zhengzhou, China, December 8-10, 2011). Vol. 452-453, p.412-416. 
[7] D. Lin, H.C. Kuo, and L.H. Wang: Chief Executive Compensation: An Empirical Study of Fat Cat CEOs, The International Journal of Business and Finance Research, Vol.7 (2013) No.2, p.27-42.

[8] B. Dai, X. Liu, and Y. Hao: Executive Power, Compensation Contract and SOEs Reform: Evidence from Listed SOEs in China, Modern Economic Science, Vol.33 (2011) No.4, p.90-98.

[9] J.X. Fang, Is Top Management Compensation of Chinese Public Companies Sticky? Economic Research, (2009) No.3, p.110-124. (In Chinese)

[10] Z. Dai, L. Jin, and W. Zhang: Executive Pay-Performance Sensitivity and Litigation, Contemporary Accounting Research, Vol.31 (2014) No.1, p.152-177.

[11] A. B. Mark: Executive Compensation Disclosure Rules: An Update of SEC Executive Compensation Disclosure (American Bar Association, American 2013)

[12] J. L. Garner, and T.D. Harrison: Boards, Executive Excess Compensation, and Shared power: Evidence from Non-profit Firms, Financial Review, Vol.48 (2013) No.4, p.617-643. 